\title{
ARTIGO
}

\section{PRECIPITAÇÕES EM GOVERNADOR VALADARES - MG E SUA RELAÇÃO COM O FENÔMENO ENOS NOS PERÍODOS CHUVOSOS DE 2008 A $2017^{1}$}

\author{
RESUMO
}

\author{
Erika Peixoto da Mota ${ }^{2}$ \\ Daniela Martins Cunha \\ Fábio Monteiro Cruz \\ Evandro Klen Panquestor
}

\begin{abstract}
Este estudo compara os dados pluviométricos das estações chuvosas do período de 2008 a 2017 do município de Governador Valadares - MG com a ocorrência do fenômeno ENOS. Para isso, foram realizadas uma pesquisa exploratória e uma revisão conceitual sobre a temática, com o uso de dados pluviométricos obtidos na Estação Meteorológica do Instituto Nacional de Meteorologia (Inmet), localizada no Instituto Federal de Minas Gerais - Campus Governador Valadares. Esses dados foram comparados com a Normal Pluviométrica, o que permitiu identificar os anos em que ocorreram volumes de chuvas acima e abaixo da média histórica esperada. Posteriormente, foram relacionados aos fenômenos El Niño e La Niña, tendo como parâmetros os dados da região do Niño 3.4. O fenômeno El Niño apresenta maior relação com os anos em que as chuvas ocorreram abaixo da média esperada para a região de estudo. Observou-se, contudo, a necessidade de estudos mais aprofundados, a fim de comparar os dados com outros fenômenos atmosféricos. Por fim, destaca-se que não somente os fatores naturais exercem influência sobre o clima, mas também os fatores antrópicos, que interferem muito no clima local, sendo também necessários mais estudos sobre a sua atuação.
\end{abstract}

Palavras-chave: Chuvas. El Niño. La Niña.

\section{INTRODUÇÃO}

Leigos utilizam clima e tempo como sinônimos, o que não é correto, uma vez que o tempo é um estado momentâneo da atmosfera de um dado lugar, enquanto o clima é uma caracterização que resulta de um longo período de estudo, entre 25 e 30 anos, com várias informações que sintetizam a atmosfera de um local ou região. "O clima depende de fatores estáticos (condições físicas do planeta) e dinâmicos (a dinâmica da atmosfera) que definem suas características" (NIMER apud OLIVEIRA; CUPOLLILO, 2012, p.2).

Segundo Mendonça, Danni-Oliveira (2007, p. 18-22):

\begin{abstract}
Os fatores do clima associados aos aspectos dinâmicos do meio oceânico e atmosférico, como correntes oceânicas, massas de ar e frentes, quando atuam juntos, irão qualificar os diferentes climas da Terra. Esses fatores correspondem às propriedades geográficas imóveis que diversificam a paisagem, como latitude, altitude, relevo, vegetação, continentalidade/maritimidade e atividades humanas.
\end{abstract}

A classificação do clima é determinada por vários fatores, dentre eles, a quantidade de radiação solar que determinada região recebe. A temperatura do ar diminui conforme a elevação da altitude, ou seja, quanto mais longe da superfície, menos aquecido, uma vez que fica mais

\footnotetext{
${ }^{1}$ Como citar este artigo: MOTA, Érika Peixoto da et al. Precipitações em Governador Valadares-MG e sua relação com o fenômeno ENOS nos períodos chuvosos de 2008 a 2017. ForScience: revista científica do IFMG, Formiga, v. 7, n. 1, e00355, jan./jun. 2019. DOI: 10.29069/forscience.2019v7n1.e355.
}

${ }^{2}$ Autor para correspondência: Érika Peixoto da Mota. E-mail: erikapmotta@gmail.com. 
rarefeito e, por consequência, mais frio. O aquecimento da Terra não ocorre de maneira uniforme entre Polos e Equador. Devido à sua forma, os raios solares atingem a região tropical quase que perpendicularmente à superfície, enquanto nas regiões mais próximas aos Polos, a incidência é oblíqua, o que implica numa maior concentração de energia por unidade de área próxima à linha do Equador. Portanto, as regiões tropicais se aquecem mais que as polares (REBOITA et al., 2012, p. 34).

O eixo de inclinação da Terra e o seu movimento de translação são fatores que determinam uma maior ou menor incidência de radiação solar sobre determinadas regiões do planeta, constituindo um importante fator climático. O movimento de translação da Terra ao redor do sol, com duração média de 365 dias junto ao seu eixo de inclinação, define as estações do ano, os solstícios de verão e inverno, quando um hemisfério recebe maior quantidade de radiação solar, e o outro, menor, respectivamente, e os equinócios de primavera e outono, quando ambos os hemisférios recebem a mesma quantidade de energia.

Outro fator que influencia nas condições da atmosfera é a diferença de aquecimento entre as superfícies.

\begin{abstract}
A capacidade térmica da água é bem maior do que a capacidade térmica da superfície continental: enquanto a água necessita de cerca de quatro unidades de energia para aquecer-se, a terra só necessita de uma unidade de energia. Portanto, o tempo necessário para aquecer e resfriar a água é maior do que para a terra. Assim, a grande capacidade térmica dos corpos d'água reduz as variações de temperatura ao longo do dia nas áreas continentais vizinhas, tanto pela proximidade quanto pela grande quantidade de vapor d'água que é proveniente do oceano e se distribui pelas regiões próximas (DIAS; DA SILVA, 2009, p. 15-21):
\end{abstract}

A vegetação também é um importante fator climático que pode interferir na distribuição da umidade e, por consequência, na ocorrência das chuvas, devido à evapotranspiração realizada por ela, principalmente em florestas densas como a Amazônia. Também influi na temperatura e na produção de ventos, ou seja, oferece conforto térmico e contribui para a produção de brisas.

Os diferentes fatores climáticos influenciam o clima do estado de Minas Gerais, atuando, assim, no clima de Governador Valadares, cidade localizada nas depressões interplanálticas do rio Doce.

\begin{abstract}
Do ponto de vista da dinâmica atmosférica, o regime climático da Bacia do Rio Doce tem características de larga escala semelhantes aos sistemas de escoamento atmosférico que atuam no estado de Minas Gerais. A grande quantidade de energia solar que atinge a região durante todo o ano origina um inverno ameno. A proximidade com a costa brasileira resulta em umidade disponível no ar tanto no inverno quanto no verão. Porém, no inverno, a atuação da circulação anti-horária e subsidente do Anticiclone Subtropical do Atlântico Sul (ASAS) e, a presença da Massa Polar Atlântica - MPA - fazem com que a região experimente um inverno seco, apesar da atuação da Frente Polar Atlântica (FPA), ao longo do litoral sudeste brasileiro. No verão, por outro lado, o efeito da circulação oceânica é minimizado pela ação das instabilidades tropicais (correntes de oeste) provenientes da Massa Equatorial Continental (MEC) conjuntamente com os sistemas frontais (FPA) que estacionam no centro e sudeste do país, podendo originar a Zona de Convergência do Atlântico Sul (ZCAS) (CLIMANÁLISE ESPECIAL, 1996 e ABREU, 1998 apud CUPOLILLO; ABREU; CASTRO, 2006, p.3).
\end{abstract}

Quadro (1994) considera a Zona de Convergência do Atlântico Sul (ZCAS) uma manifestação atmosférica natural do verão com grandes índices de precipitações em boa parte do território brasileiro, identificada como um corredor de nebulosidade, no sentido noroeste/sudeste, estendendo do sul da Amazônia ao Atlântico Sul-Central por vários quilômetros. 
Além disso, no período chuvoso, os núcleos de baixa pressão, conhecidos por Linhas de Instabilidade Tropical (IT), depressões barométricas induzidas ou calhas induzidas, também são responsáveis pelas chuvas no estado de Minas Gerais. Para alguns autores, elas estão relacionadas à configuração do anticiclone subtropical, que atua com pouca intensidade nesta época do ano (ABREU, 1998). “As IT são centros de baixa pressão, semiestacionários, observados durante a primavera e o verão, e que, como mencionado por Nimer, estão associadas ao intenso aquecimento do continente brasileiro nestas estações" (ABREU, 1998, p. 18).

Além dos mecanismos da dinâmica atmosférica global que atuam em Minas Gerais já mencionados, pode-se citar, também, o El Niño Oscilação Sul (ENOS).

O ENOS se caracteriza por alterações ou anomalias da temperatura da superfície do mar (TSM) na região do Pacífico Equatorial próximo à Costa Oeste da América do Sul. A condição normal de TSM na região Central da bacia do Oceano Pacífico é a concentração de águas quentes na parte oeste e de águas frias na região leste. A essa condição normal das águas do Oceano Pacífico denomina-se de ano Neutro ou Neutralidade Climática. Quando as águas quentes migram para a região leste da bacia do Pacífico equatorial, define-se o El Niño, onde a anomalia de TSM é positiva, enquanto a La Niña é caracterizada quando a anomalia de TSM na região é negativa (GRIMM et al.; BERLATO; FONTANA apud SALINI, 2011, p.12) (Figura 1).

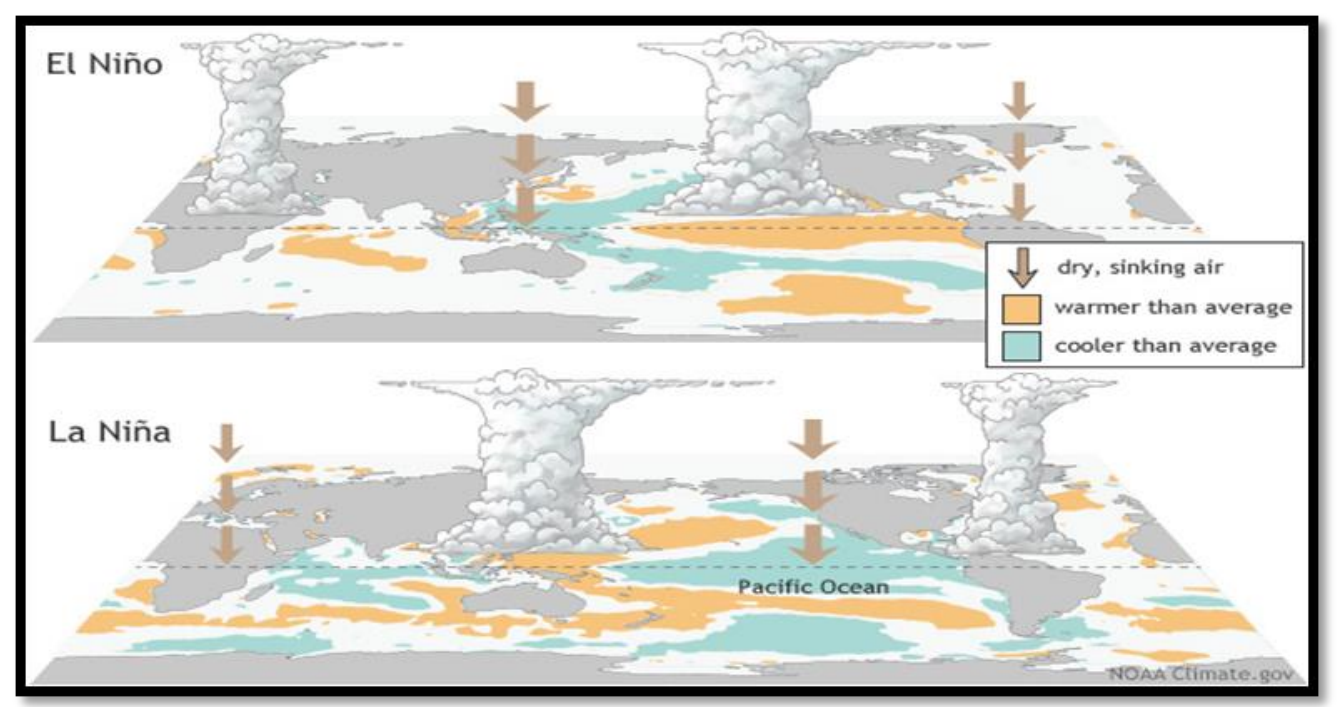

Figura 1 - El Nino e La Nina

Fonte: Climate.gov (2019) ${ }^{3}$.

O El Nino, segundo o Instituto Nacional de Pesquisas Espaciais (INPE), representa o aquecimento anormal das águas superficiais e subsuperficiais do Oceano Pacífico Equatorial, considerando-se não somente a presença das águas quentes da Corrente El Niño, mas também as mudanças na atmosfera próxima à superfície do oceano, com o enfraquecimento dos ventos alísios (que sopram de leste para oeste) na região equatorial. Com esse aquecimento do oceano e o enfraquecimento dos ventos, começam a ser observadas mudanças da circulação da atmosfera nos níveis baixos e altos, determinando alterações nos padrões de transporte de umidade e, portanto, variações na distribuição das chuvas em regiões tropicais e de latitudes médias e altas, sendo que, em algumas regiões do globo terrestre, também se percebe aumento ou queda de temperatura. Já o fenômeno La Niña, ou episódio frio do Oceano Pacífico, é o "resfriamento anômalo das águas superficiais no Oceano Pacífico Equatorial Central e Oriental" (RIZZI; LOPES; MALDONADO, 2001) (Figura 1).

\footnotetext{
${ }^{3}$ www.climate.gov/enso.
} 
Os fenômenos El Niño e La Niña são muito complexos e, por mais que se encontrem estudos sobre a sua influência nas precipitações em Minas Gerais e no Brasil, observa-se que ainda não há descrições de consequências concretas. Isso se deve, até mesmo, às diferentes intensidades que o fenômeno pode assumir e ao caráter de região de transição climática existente no sudeste do Brasil, onde os eventos se deslocam para o norte ou para o sul com grande facilidade.

O Estado de Minas Gerais, "por sua localização geográfica, sofre a influência de fenômenos meteorológicos de latitudes médias e tropicais que imprimem à região características de um clima de transição. Duas estações bem definidas podem ser identificadas: uma seca e uma chuvosa" (ABREU, 1998, p. 17). A estação seca ocorre no período de abril a setembro, e a estação chuvosa, de outubro a março, analogamente ao que ocorre na Bacia do Rio Doce e no município de Governador Valadares.

Assim, o objetivo geral deste estudo foi comparar os dados pluviométricos das estações chuvosas do período de 2008 a 2017, do Município de Governador Valadares, com a ocorrência do fenômeno ENOS. E, como objetivos específicos: obter os dados pluviométricos do período chuvoso de 2008 a 2017 e relacioná-los à Normal Climatológica Pluviométrica do município de Governador Valadares, e identificar a variação dos dados de chuva, conforme os totais obtidos para o período, e associá-los à ocorrência do ENOS.

\section{PROCEDIMENTOS METODOLÓGICOS}

\section{1 Área de estudo}

De acordo com o Instituto Brasileiro de Geografia e Estatística (IBGE), o município de Governador Valadares está localizado na interseção das coordenadas geográficas de latitude $18^{\circ} 95^{\prime}$ S e longitude $41^{\circ} 94^{\prime} \mathrm{W}$, na região Leste de Minas Gerais (Figura 2), com uma área de $2.355 \mathrm{~km}^{2}$, altitude média de 140 metros e uma população de 263.689 habitantes (IBGE, 2010). O município localiza-se, ainda, na microrregião de Governador Valadares, que, por sua vez, está inserida na mesorregião do Vale do Rio Doce.

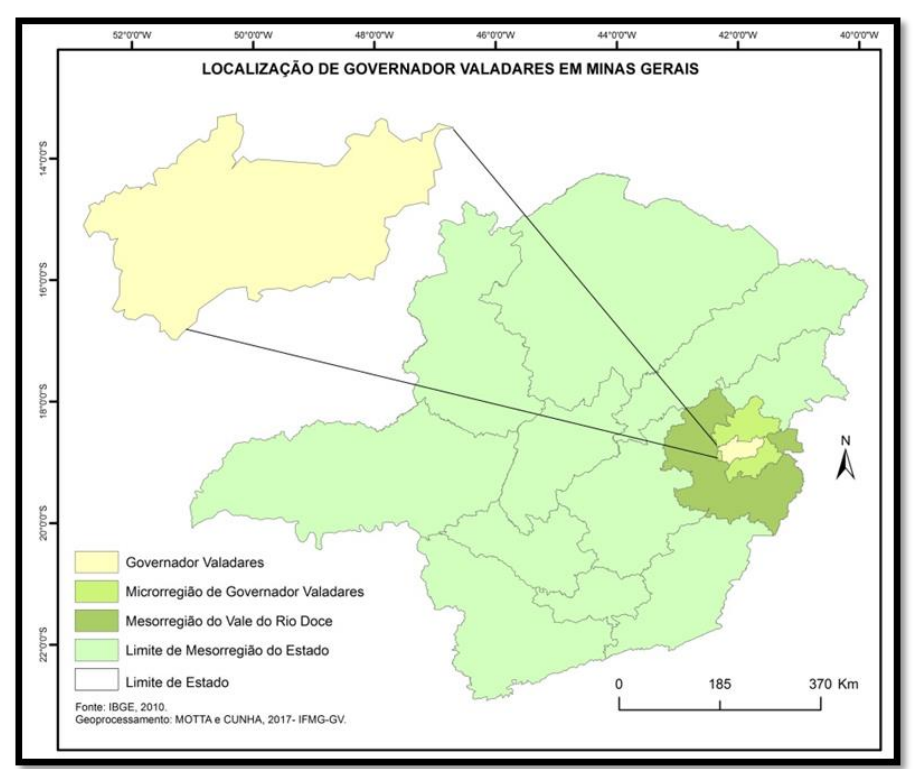

Figura 2- Mapa de localização de Governador Valadares em Minas Gerais Fonte: IBGE (2010). 
Ainda segundo o IBGE, o município possui poucas regiões de vegetação nativa, devido ao grande desmatamento que ocorreu no início da colonização da região, por volta de 1907, sendo a extração de madeira a principal atividade econômica e, depois, a pecuária extensiva, que também é bastante representativa. O município se encontra na Bacia do Rio Doce, que é o principal rio dessa bacia e responsável por todo o abastecimento de água na região.

\subsection{Classificação climática da área de estudo}

O desenvolvimento de estudos relacionados ao clima começou a partir da Revolução Tecnológica Renascentista, quando diversos instrumentos foram inventados. Inicialmente, o estudo do tempo e do clima era realizado a partir de uma abordagem descritiva, que se preocupava com o padrão de distribuição espacial e temporal dos elementos do tempo - a climatologia tradicional. A ênfase da climatologia atual, considerada moderna, é a explicação dos fenômenos atmosféricos, além de sua descrição. A moderna climatologia surgiu do aprimoramento tecnológico no processo de coleta e análise dos dados, assim como dos desafios da sociedade (AYOADE, 2003).

Segundo Barry e Chorley (2013, p. 4), "durante o século XIX, tornou-se possível montar um grande banco de dados climáticos e usá-los para fazer generalizações regionais". Os autores destacam ainda a produção do tratado sobre temperaturas globais contendo um mapa de isotermas do hemisfério norte, realizado por Humboldt, em 1817, além de outras produções, como a de Koppen, que, em 1870, começou a produzir mapas climáticos com base na geografia vegetal, e, em 1918, produziu a primeira classificação climática mundial detalhada com base na cobertura vegetal terrestre (BARRY; CHORLEY, 2013).

A definição e a classificação do clima de uma região resultam de uma série de estudos e comparações, nos quais os fatores climáticos e meteorológicos são levados em consideração. Segundo Rolin et al. (2007), o sistema mais completo de classificação climática é o de Koppen, aperfeiçoado nos anos de 1918, 1927 e 1936, com a colaboração do meteorologista e climatologista Rudolf Oskar Robert Williams Geiger. Este sistema ficou conhecido como Koppen e Geiger. Para os autores, a vegetação natural de cada grande região da Terra torna-se uma expressão do clima predominante (ROLIN et al., 2007).

Na visão de Vianello e Alves (2000), Wladimir Koppen (1846-1940) utilizou como referência o mapa de vegetação mundial de De Candolle elaborado em 1855, fisiologista francês, definindo, assim, que a vegetação natural é a melhor forma de classificação do clima. A partir de 1901, publicou sua primeira classificação climática, sendo aprimorada diversas vezes. Mais tarde, veio a acrescentar nas classificações a temperatura, as chuvas e as características sazonais. Dividiu o clima mundial em cinco grandes grupos, juntamente com mais onze principais tipos, oferecendo, dessa forma, uma gama de detalhes para o nível desejado. Com um estudo primário das classificações climáticas, conhecendo valores de temperatura e precipitações, os pesquisadores têm acesso a dados e informações críveis acerca do clima.

Para Camargo e Camargo (2000, p. 126): 
O conceito de evapotranspiração potencial, o mais significativo avanço no conhecimento dos aspectos da umidade climática, foi introduzido em 1944 por Thornthwaite, quando trabalhava com problemas de irrigação, no México (MATHER, 1958). A evapotranspiração potencial (ETp) passou a ser considerada, como a chuva, um elemento meteorológico padrão, fundamental, representando a chuva necessária para atender às carências de água da vegetação (CAMARGO; CAMARGO, 2000, p. 126).

Segundo Nascimento; Luiz e Oliveira (2016, p.71):

\begin{abstract}
A classificação climática proposta por Strahler (1969) é sem dúvida uma das mais utilizadas, tanto no ambiente científico como no cotidiano - e por isso mesmo é muito divulgada em livros didáticos. Baseado nas características dos regimes das massas de ar e nos elementos precipitação e temperatura, o autor divide os climas do globo terrestre em quatro principais grupos: os climas das latitudes baixas, controlados pelas massas de ar equatoriais e tropicais; os climas das latitudes médias, controlados pelas massas de ar tropicais e polares; os climas das latitudes altas, controlados pelas massas de ar polares; e o clima das grandes altitudes, onde o relevo é o fator determinante. Esses grandes grupos climáticos são subdivididos em 13 zonas climáticas (NASCIMENTO; LUIZ; OLIVEIRA, 2016, p. 71).
\end{abstract}

Observa-se, conforme as metodologias de classificação climática apresentadas, que Governador Valadares, na classificação de Koppen, possui clima Aw, ou seja, clima tropical com inverno seco, sendo bem definidas a estação chuvosa, no verão, e a estação seca no inverno. Pela classificação de Thornthwaite, possui clima quente e semiúmido, com poucas chuvas no verão, e seco no inverno; e, pela classificação de Strahler, que considera as influências das massas de ar, possui clima tropical alternadamente úmido e seco, verão (chuvoso) e inverno (seco). Em resumo, verifica-se, em todas as classificações citadas, que o município de Governador Valadares apresenta duas estações ao longo do ano: seis meses de verão (úmido) e seis meses de inverno (seco), o que reafirma a escolha do período de estudo, pois são três classificações com a mesma realidade.

\title{
2.3 Material e Métodos
}

Este estudo baseou-se em uma pesquisa exploratória, que tem como principal finalidade "desenvolver, esclarecer e modificar conceitos e ideias, tendo em vista a formulação de problemas mais precisos ou hipóteses pesquisáveis para estudos posteriores" (GIL, 2008, p.46). Utilizou-se uma revisão conceitual, por meio de pesquisa bibliográfica, para obter informações, interpretações e reflexões atuais sobre as diversas temáticas e conceitos a serem tratados no decorrer do trabalho. Tais leituras tiveram como foco estudos prévios de diversos autores e suas obras, como livros, periódicos científicos, dissertações de mestrado e teses de doutorado, bem como anais de eventos científicos, como simpósios e congressos.

Os dados pluviométricos mensais utilizados foram os da estação chuvosa relativos aos períodos de outubro a março dos anos de 2008 (outubro) a 2017 (março), obtidos na Estação Meteorológica Automática do Instituto Nacional de Meteorologia (Inmet), localizada no Instituto Federal de Minas Gerais (IFMG), campus Governador Valadares, e tratados no Microsoft Excel. Salienta-se que foi descartado o período chuvoso de outubro de 2014 a março de 2015 pela ausência de dados, devido ao fato de a estação não ter operado no início de 2015 por problemas técnicos. 
Após o levantamento dos dados, eles foram comparados aos dados da Normal Pluviométrica obtidos em Reis; Guimarães; Landau (2012), a fim de verificar os desvios, principalmente aqueles que indicaram o déficit e o excedente de chuvas. Em seguida, buscou-se relacionar esses períodos com o fenômeno atmosférico ENOS, com o objetivo de compará-los em termos de período de ocorrência.

O evento ENOS foi selecionado por meio do índice da região 3.4 (Figura 3). Segundo Philander e Glantz, apud Salini (2011), o componente oceânico desta região foi marcado por apresentar anomalias da Temperatura da Superfície do Mar (TSM) do Oceano Pacífico Equatorial próximo à costa oeste da América do Sul, sendo a região monitorada através de sua temperatura.

Historicamente, os cientistas classificaram a intensidade do El Niño com base em anomalias TSM que ultrapassavam um limite pré-selecionado em uma determinada região do Pacífico equatorial. A região mais comumente utilizada é a região de Niño 3.4, e o limiar empregado com maior frequência é o aumento da TSM normal, para valores maiores ou iguais a $+0.5{ }^{\circ} \mathrm{C}$. Uma vez que esta região abrange a metade ocidental da região equatorial fria, proporciona mudanças importantes nos gradientes de TSM e TSM, que resultam em alterações no padrão de convecção tropical profunda e na circulação atmosférica. Os critérios frequentemente utilizados para classificar os episódios de El Niño são cinco anormalidades de TSM significativas e consecutivas em um período de 3 meses. Estudos têm demonstrado que uma condição necessária para o desenvolvimento e a persistência da convecção profunda (maior nubosidade e precipitação) nos trópicos é que a TSM local seja de $28{ }^{\circ} \mathrm{C}$ ou superior. Uma vez que o padrão de convecção profunda foi alterado devido a TSM anômalas, a circulação atmosférica tropical e subtropical se ajusta ao novo padrão de aquecimento tropical, resultando em padrões anômalos de precipitação e temperatura que se estendem muito além da região do Pacífico equatorial. Uma anomalia de TSM de $+0,5^{\circ} \mathrm{C}$, na região Niño 3.4, é suficiente para alcançar esse limite de final de março a meados de junho. Durante o restante do ano, é necessária uma maior anomalia de $\mathrm{TSM}$, até $+1,5^{\circ} \mathrm{C}$, em novembro-dezembro-janeiro, para atingir o limite para suportar convecção profunda persistente nessa região (NOAA, 2017, tradução nossa).

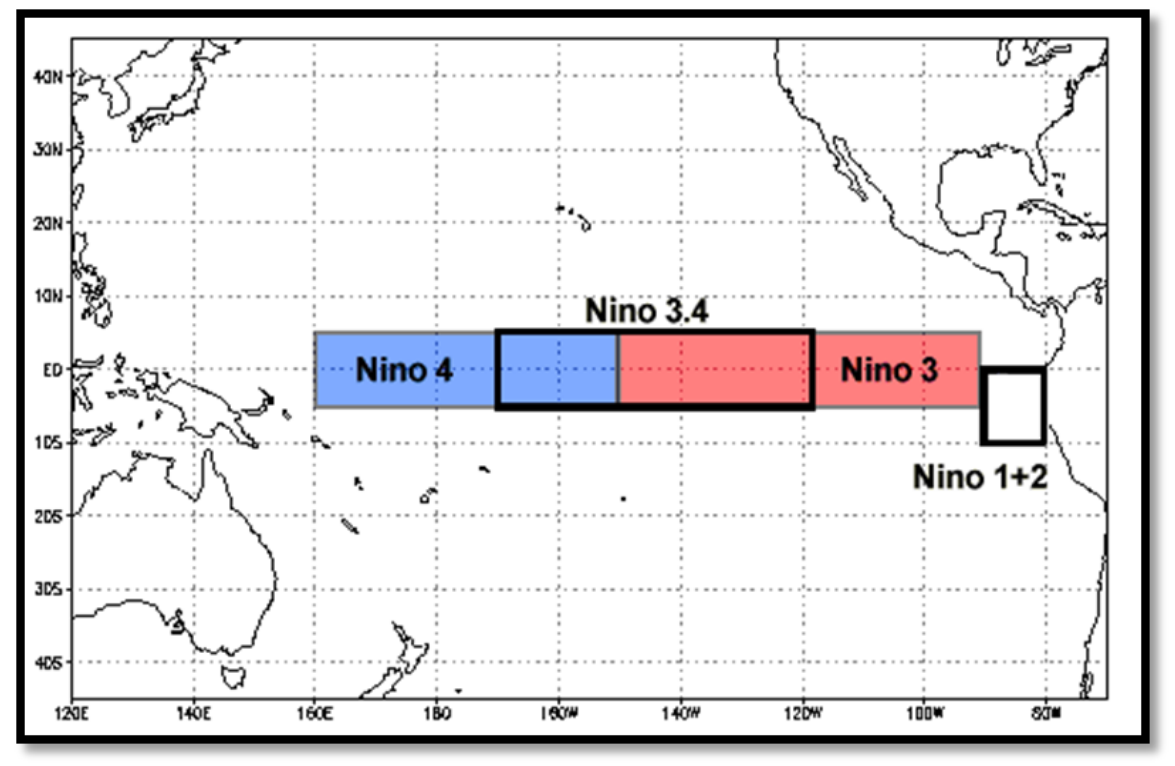

Figura 3 - Região de Nino Fonte: NOAA (2017). 


\section{RESULTADOS E DISCUSÃO}

Conforme pode ser observado na Figura 4, os períodos chuvosos em Governador Valadares, de outubro de 2008 a março de 2017, foram marcados por meses em que predominou um volume de chuvas abaixo do esperado em relação à média da Normal Pluviométrica, merecendo destaque o mês de janeiro de 2010, fevereiro dos anos de 2012, 2014 e 2016, e outubro de 2008 e 2015. Pôde-se também verificar que, em alguns períodos, ocorreram chuvas acima da Normal Pluviométrica em dois meses pelo menos, como em dezembro de 2013.

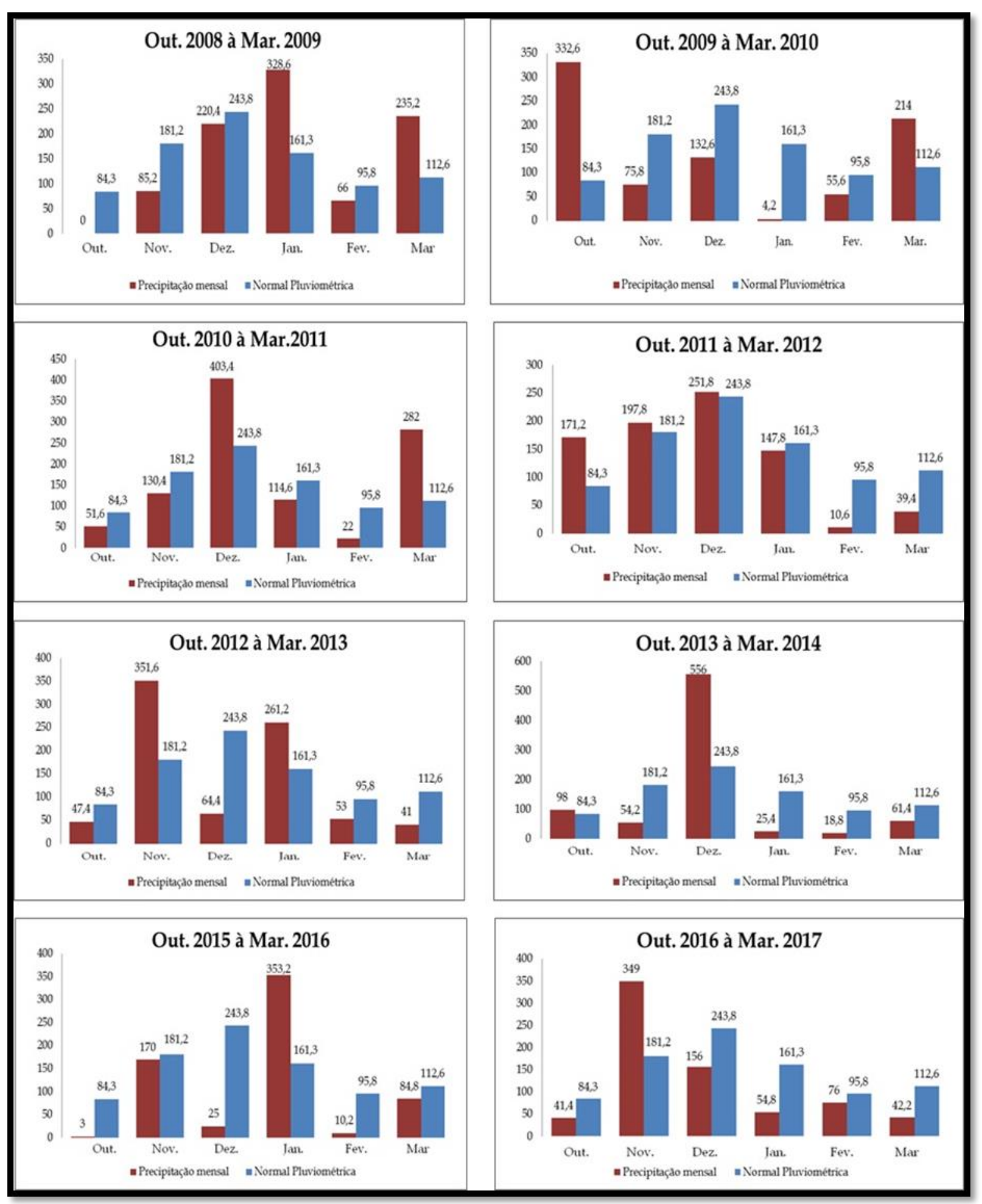

Figura 4 - Precipitação mensal e normal pluviométrica dos períodos chuvosos de outubro de 2008 a março de 2017 Fonte: Estação Meteorológica do Inmet (2017).

Por outro lado, quando se observa o total de chuvas de cada período chuvoso, verifica-se que as precipitações ocorreram com valores bem próximos à Normal Pluviométrica, ou até mesmo acima desta, como nos períodos de outubro de 2008 a março de 2009, e outubro de 2010 
a março de 2011. Já os períodos com precipitações abaixo da Normal Pluviométrica mais acentuadas foram de outubro de 2015 a março de 2016, e de outubro de 2016 a março de 2017.

Nota-se, ainda, para o período estudado, que há uma linha indicando uma tendência de diminuição do total de chuvas ao longo dos anos (Figura 5). A má distribuição mensal das precipitações, assinaladas e observadas na Figura 4, não condiz, em sua plenitude, com o total de chuvas esperado para cada período chuvoso, como pode ser visualizado na Figura 5, pois há meses com extrema escassez ou com grande excedente.

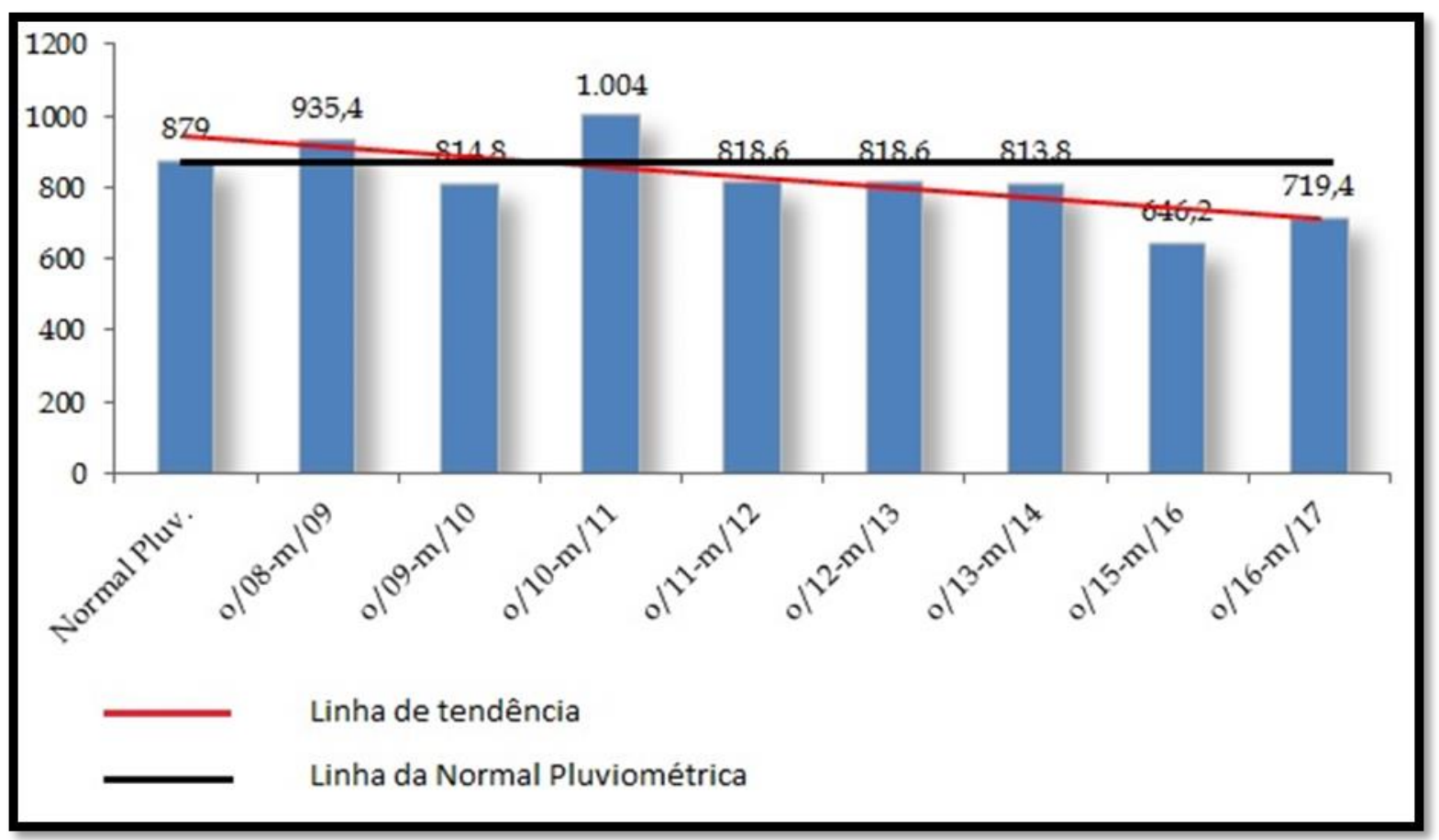

Figura 5 - Total de precipitação por período chuvoso comparado à Normal Pluviométrica Fonte: Estação Meteorológica do Inmet (2017).

As chuvas abaixo e acima da média mensal ocorridas em boa parte desses meses, assim como o volume total de chuvas para cada período abaixo ou acima da Normal Pluviométrica, podem ser explicadas, dentre outros fatores, pelo fenômeno atmosférico ENOS.

De acordo com a Figura 6, considerando-se o período chuvoso em estudo, ou seja, de 2008 a 2017, pode-se assinalar a ocorrência do fenômeno El Niño nos períodos de 2009-2010 e 2015-2016, e da La Niña em 2008-2009, 2010-2011 e 2011-2012. Os demais períodos são considerados de normalidade, exceto 2014-2015, que foi de El Niño, mas não será comentado devido à ausência de dados de precipitação.

Comparando as informações descritas acima com os dados dos gráficos (Figuras 4 e 5), observa-se que, nos períodos de El Niño, 2009-2010 e 2015-2016, as precipitações totais ocorreram abaixo da Normal, em especial, no último. Destaca-se que, na fase "madura" do evento, geralmente nos meses de dezembro e janeiro (SILVA apud MINUZZI, 2003), as precipitações ocorreram bem abaixo da média, excetuando-se apenas o mês de janeiro de 2016.

Já nos períodos de La Niña, nota-se que, na estação chuvosa de 2008-2009, houve um acréscimo nas precipitações comparadas à Normal Pluviométrica, sendo que o mês de janeiro de 2009 apresentou o maior total pluviométrico. No período de 2010 a 2011, percebeu-se, no início da estação chuvosa, um decréscimo comparado à Normal Pluviométrica, mas, a partir de dezembro de 2010, houve um acréscimo considerável nas precipitações, em especial neste mês. 
Apenas no período de 2011-2012, o total pluviométrico ocorreu abaixo da Normal, sendo que os três primeiros meses do ano de 2012 foram os que contribuíram para este decréscimo.

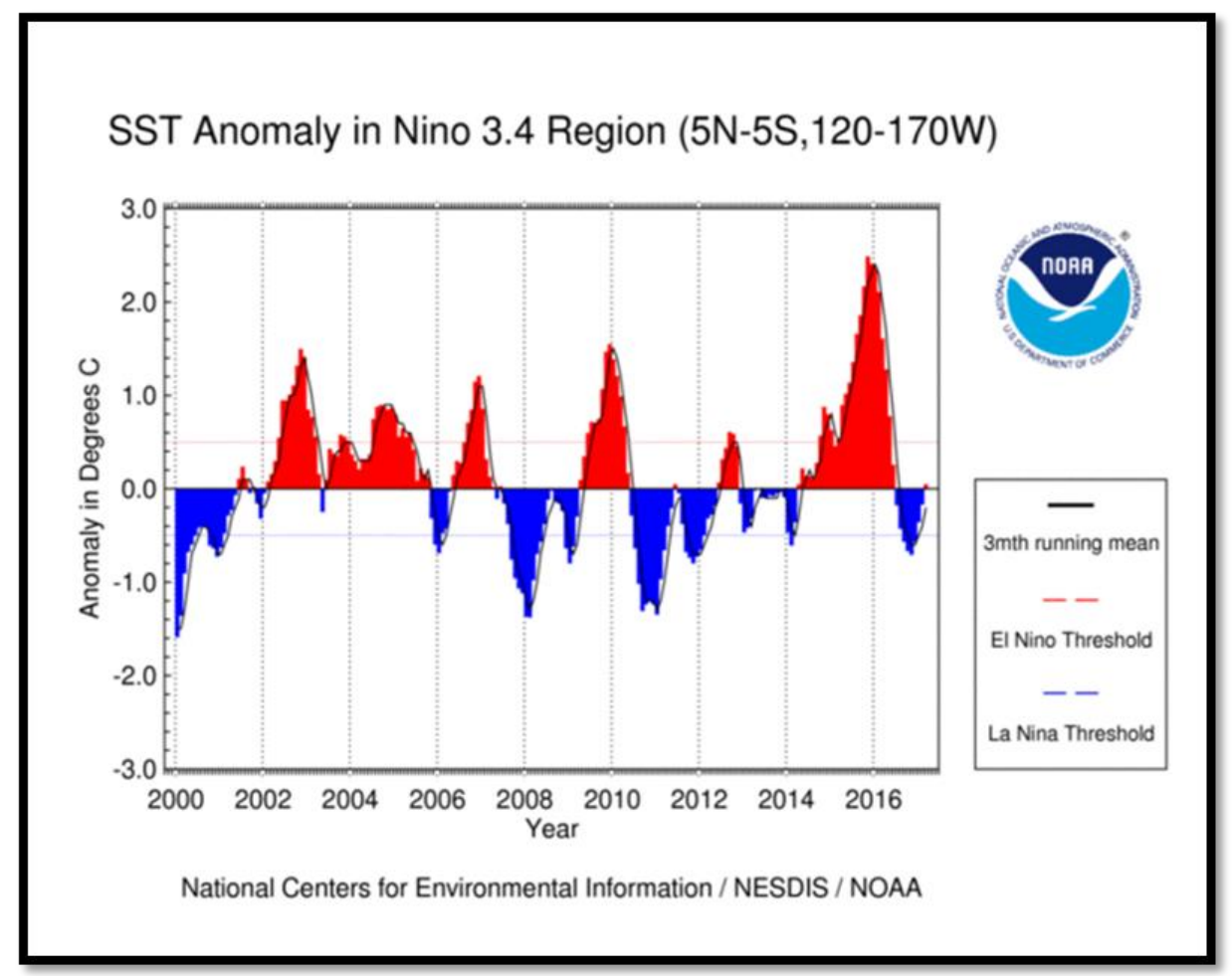

Figura 6 - Anomalia de temperatura na região do Niño 3.4 Fonte: NOAA (2017).

Nos períodos considerados de normalidade - 2012-2013 e 2013-2014 - os totais pluviométricos também estiveram um pouco abaixo da Normal e mal distribuídos mensalmente, merecendo destaque o mês de dezembro de 2013, com 556 mm de chuva, e janeiro de 2014, com apenas 25,4 mm. O período 2016-2017 foi marcado pela transição do El Niño, que começou a perder força, no final de 2016, para uma situação de normalidade de temperatura na região 3.4 (conforme Figura 6) no início de 2017. No que se refere ao total de chuvas, este período também ficou abaixo da Normal, destacando-se, principalmente, o déficit de chuvas ocorrido de janeiro a março de 2017.

Minuzzi (2003) apresenta diversos trabalhos que ressaltam as consequências do El Niño e da La Niña na região Sudeste do Brasil. Dentre eles, está o de Quadro (1993), que sugere que, durante o El Niño, as ZCAS ficam inibidas ou se formam fora de sua região de ocorrência, o que reforça a explicação da diminuição de chuvas em Governador Valadares em anos de El Nino; e o de Fedorova, Carvalho e Silva (2017), que, ao comparar determinados períodos, concluiu que a formação de ZCAS é maior no ano de La Niña que de El Niño ou de normalidade, sendo que as ZCAS ocorreram mais entre as latitudes de $22^{\circ}$ a $30^{\circ}$, o que não influencia a região de Governador Valadares.

Pelos trabalhos apresentados por Minuzzi (2003), dentre outros, e pelas relações efetuadas neste estudo entre o fenômeno ENOS e o comportamento pluviométrico encontrado nos diferentes períodos chuvosos, pode-se concluir que as influências do El Niño, ainda que pequenas quando se pensa em volume total de chuvas, são mais evidentes que as da La Niña em Governador Valadares. 


\title{
4 CONSIDERAÇÕES FINAIS
}

Pelo presente trabalho, exploratório, não se chega a conclusões, mas a apontamentos que mostram que, em alguns períodos de maior/menor índice pluviométrico, é possível fazer uma relação com o fenômeno ENOS, em especial o El Niño, que desloca as ZCAS mais para o sul do País, impedindo que elas atuem sobre a região do município. Observou-se também que, em termos de total de chuvas, apenas no período de El Niño 2015-2016, o déficit foi realmente acentuado e ocorreu, de modo geral, uma desconcentração das chuvas nos meses dos períodos chuvosos, havendo alguns com déficit elevado e outros com alto excedente, o que indica a necessidade de mais estudos que possam verificar o ocorrido e o que causou tais anomalias.

Ressalta-se, ainda, que este estudo levou em consideração somente informações de uma Estação Meteorológica, localizada em um Campus do IFMG, sendo uma área considerada rural. Ou seja, os resultados obtidos não encerram a temática - ao contrário, indicam a necessidade de novos estudos que considerem um volume maior de dados e os integrem a outros fenômenos atmosféricos, como as ZCAS, a Alta da Bolívia, a formação de cavados, a atuação da ASAS (Alta Subtropical do Atlântico Sul), dentre outros, a fim de compreender melhor as influências que os fenômenos ENOS podem exercer sobre Minas Gerais e, em especial, sobre o município de Governador Valadares.

São muitos os fatores que determinam o clima, não só os naturais, mas também os antrópicos. Cada vez mais, surgem preocupações com o que ocorrerá com a Terra em virtude das variações climáticas. É necessário entender o que é efeito antrópico e efeito natural, que já ocorrem há milhares de anos, para se ter consciência do papel dos seres humanos enquanto habitantes desse planeta, no cuidado e na consciência coletiva, que visam garantir os recursos naturais por meio de ações voltadas à preservação, recuperação e fiscalização de ações antrópicas, afinal, é necessário que o planeta tenha condições de ser habitado.

Diante dos fenômenos climáticos naturais, também podem ser citados os de natureza antrópica, ou seja, que atuam localmente, como o uso desordenado do solo, o desmatamento, a pecuária extensiva e as queimadas - fatores que contribuem para a alteração do ciclo hidrológico, que, por sua vez, afeta o clima local. Estudos apontam que, quanto mais vegetação possuir uma localidade, mais a região será úmida, ocorrendo mais evaporação e evapotranspiração, contribuindo, assim, para o aumento de precipitação e a ocorrência do ciclo da água. Por fim, ressalta-se que são necessárias mais pesquisas sobre as influências antrópicas no clima local.

\section{PRECIPITATIONS IN GOVERNADOR VALADARES, MG AND ITS RELATIONSHIP WITH THE PHENOMENON ENSO IN THE RAINY PERIODS OF 2008 TO 2017}

\begin{abstract}
This study compares rainfall data from rainy season from 2008 to 2017 in the municipality of Governador Valadares-MG with the occurrence of the ENSO phenomenon. For that, an exploratory research was carried out, conceptual revision on the subject and pluviometric data obtained from the Instituto Nacional de Meteorologia (Inmet) Meteorological Station, located at
\end{abstract}


the Federal Institute of Minas Gerais, Governador Valadares campus. The data obtained at the station were compared with the Normal Rainfall, which allowed identifying years in which rainfall volumes occur above and below the expected historical average and, later, related to the El Niño and La Niña phenomena, having as parameter the data of the region of the Nino 3.4. The El Niño phenomenon presents a greater relation with the years in which the rains occurred below the average expected for the study region. However, there is a need for more in-depth studies in order to compare the data with other atmospheric phenomena. Finally, there are not only natural factors influencing the climate, but also anthropic factors that have a great influence on the local climate, and further studies on their performance are necessary.

Keywords: Rainfall. El niño. La niña.

\section{REFERÊNCIAS}

ABREU, Magda Luzimar de. Climatologia da Estação Chuvosa de Minas Gerais: de NIMER (1977) à Zona de Convergência do Atlântico Sul. Revista Geonomos, Belo Horizonte, v. 6, n. 2 , p.17-22, 1998.

AYOADE, J. O. Introdução à climatologia para os trópicos. Rio de Janeiro: Bertrand Brasil, 1996. $332 \mathrm{p}$.

BARRY, Roger G.; CHORLEY, Richard J. Atmosfera, tempo e clima. Tradução: COSTA, Ronaldo Cataldo. 9. ed. Porto Alegre: Bookman, 2013. 512 p.

CAMARGO, Ângelo Paes; CAMARGO, Marcelo Bento Paes de. Uma revisão analítica de evapotranspiração potencial. Bragantia, Campinas, v. 59, n. 2, p. 125-137, 2000.

CUPOLILLO, Fúlvio; ABREU, Magda Luzimar de; CASTRO, Frederico do Valle Ferreira de. Climatologia do regime pluviométrico na Bacia do Rio Doce. In: XIV CONGRESSO BRASILEIRO DE METEOROLOGIA, 2006, Florianópolis. Anais. Rio de Janeiro: SBMET, 2006.

DIAS, Maria Assunção Faus da Silva; DA SILVA, Maria Gertrudes Alvarez Justi. Para entender tempo e clima. In: CAVALCANTI, Iracema Fonseca de Albuquerque; FERREIRA, Nelson Jesus; DA SILVA, Maria Gertrudes Alvarez Justi; DIAS, Maria Assunção Faus da Silva (orgs.). Tempo e Clima no Brasil. São Paulo: Oficina de Textos. 2009. 464f.

FEDOROVA, Natália; CARVALHO, Maria Helena de; SILVA; Rogério de Souza e. Processos Sinóticos em anos de La Niña e de El Niño. Parte II: Zonas Frontais. Revista Brasileira de Meteorologia, São José dos Campos, v.15, n.2, p. 57-72, 2000.

GIL, Antônio Carlos. Métodos e técnicas de pesquisa social. 6. ed. São Paulo: Atlas, 2008.

IBGE-INSTITUTO BRASILEIRO DE GEOGRAFIA E ESTATÍSTICA. Censo demográfico de 2010. Disponível em: http://cidades.ibge.gov.br/painel/historico.php?codmun=312770. Acesso em: 02 maio 2017.

INPE-INSTITUTO NACIONAL DE PESQUISAS ESPACIAIS. EL Niño. Disponível em: http://enos.cptec.inpe.br/elnino/pt. Acesso em: 25 mar. 2017.

MENDONÇA, Francisco; DANNI- OLIVEIRA, Inês Moresco. Climatologia: noções básicas e climas do Brasil. São Paulo: Oficina de Textos, 2007. 206p. 
MINUZZI, Rosandro Boligon. Influência dos fenômenos EI Niño e La niña nos veranicos no Estado de Minas Gerais. 2003, 113f. Tese (Doutorado em Meteorologia Agrícola)- PósGraduação em Meteorologia Agrícola, Universidade Federal de Viçosa, Viçosa, 2003.

NASCIMENTO, Diego Tarley Ferreira; LUIZ, Gislaine Cristina; OLIVEIRA, Ivanilton José de. Panorama dos sistemas de classificação climática e as diferentes tipologias climáticas referentes ao Estado de Goiás e ao Distrito Federal (Brasil). Revista de Geografia da UEG, Goiás, v. 5, n. 2, 2016.

NOAA- National Oceanic and Atmospheric Administration. Equatorial pacific sea surface temperatures. Disponível em:

https://www.ncdc.noaa.gov/teleconnections/enso/indicators/sst.php. Acesso em: 19 maio 2017.

OLIVEIRA, Weydna Bethânia Alves; CUPOLILLO, Fúlvio. Estudo do clima urbano de Governador Valadares-MG. 2012, 26f. Trabalho de Conclusão de Curso (Tecnologia em Gestão Ambiental) - Instituto Federal de Minas Gerais, Campus Governador Valadares, Governador Valadares, 2012.

QUADRO, Mário Francisco Leal. Estudo de episódios de Zona de Convergência do Atlântico Sul (ZCAS) sobre a América do Sul. 1994. 94f. Dissertação (Mestrado em Meteorologia) Instituto Nacional de Pesquisa Espaciais, São José dos Campos, 1994.

REBOITA, Michele Simões et al. Entendendo o Tempo e o Clima na América do Sul. Terrae Didática. Campinas, v. 1, n. 8, p. 34-50, 2012.

REIS, Ruibran Januário dos.; GUIMARÃES, Daniel Pereira; LANDAU, Elena Charlotte. Chuvas em Minas Gerais. Belo Horizonte: PUC Minas, 2012.

ROLIN, Glauco de Souza et al. Classificação climática de Koppen e de Thornthwaite e sua aplicabilidade na determinação de zonas agroclimáticas para o estado de São Paulo. Bragantia, Campinas, v. 66, n. 4, p. 711-720, 2007.

RIZZI, Rodrigo; LOPES, Pabrício; MALDONADO, Francisco. Influência dos Fenômenos El Niño e La Niña no rendimento da cultura da Soja no RS. 2001, 36f. Trabalho Final de Análise Espacial (Especialização em Sensoriamento Remoto) - Pós-Graduação em Sensoriamento Remoto, Instituto Nacional de Pesquisas Espaciais. São José dos Campos, 2001.

SALINI, Michelini Finatto. Influência do Fenômeno El Niño Oscilação Sul - ENOS (La Niña e El Niño) na ocorrência de inundações no vale do Taquari-RS. 2011, 57f. Trabalho de Conclusão de Curso (Curso de Engenharia Ambiental) - Centro Universitário UNIVATES, Lageado, 2011.

VIANELLO, Rubens Leite; ALVES, Adil Rainier. Meteorologia básica e aplicações. 2. ed. Viçosa: UFV, 2000.

\section{DADOS DOS AUTORES}

\section{Erika Peixoto da Motta}

E-mail: erikapmotta@gmail.com

Lattes: http://lattes.cnpq.br/3601170036217780

Tecnóloga em Gestão Ambiental pelo Instituto Federal de Educação, Ciência e Tecnologia de Minas Gerais- IFMG - Campus Governador Valadares. 


\section{Daniela Martins Cunha}

E-mail: daniela.cunha@ifmg.edu.br

Lattes: http://lattes.cnpq.br/2137302689764585

Doutoranda em Geografia - Tratamento da Informação Espacial pela PUC-Minas, mestre em Extensão Rural pela Universidade Federal de Viçosa (UFV), especialista em Estudos Ambientais pela PUC-Minas e licenciada em Geografia pela Faculdade de Filosofia, Ciências e Letras de Caratinga. Atualmente é professora de Climatologia e Poluição Atmosférica do Curso Técnico Integrado em Meio Ambiente e professora de Cartografia e Climatologia do Curso Superior em Tecnologia em Gestão Ambiental no IFMG - Campus Governador Valadares.

\section{Fábio Monteiro Cruz}

E-mail: fabio.cruz@ifmg.edu.br

Lattes: http://lattes.cnpq.br/2828152228543615

Engenheiro Ambiental e mestre pelo programa interinstitucional de pós-graduação em Ciências Ambientais UFPA/MUSEU GOELDI/EMBRAPA AMAZÔNIA ORIENTAL. Atualmente é professor pesquisador do IFMG - Campus Governador Valadares.

\section{Evandro Klen Panquestor}

E-mail: evandro.klen@ifmg.edu.br

Lattes: http://lattes.cnpq.br/7973038275576858

Doutor em Geografia - Ordenamento Territorial Ambiental pela Universidade Federal Fluminense (UFF). Possui mestrado em Geografia pela Universidade de Brasília (UnB) com ênfase em geoprocessamento e análise da paisagem. Especialista em Planejamento, Implementação e Gestão da Educação a Distância pela UFF. Graduado em Geografia pela UnB (licenciatura e bacharelado). Atualmente é professor do IFMG - Campus Governador Valadares, atuando no Ensino Médio Técnico Integrado e no Ensino Superior. 